\title{
GENERATING IMPACT IN TRANSNATIONAL HUMANITIES RESEARCH: HERA 2009-2018
}

Prof. Dr. Wojciech Sowa: HERA Network Chair, Narodowe Centrum Nauki, Poland (Wojciech.Sowa@ncn.gov.pl)

Prof. Dr. Tony Whyton: HERA Knowledge Exchange \& Impact Fellow

Birmingham City University, UK (Tony.Whyton@bcu.ac.uk)

\section{HERA IMPACT CASE STUDIES}

Innovation in humanities research demonstrated by HERA-funded projects leads to diversity in impact. Through contrasting processes and methods of engagement outside the academy, researchers have developed new ways of both conceiving and addressing research challenges that are central to realizing the European Research \& Innovation agenda.

As examples, we identify five distinctive areas of HERA project impact and associated policy implications that create social, economic and cultural benefits for 'action' and 'reflection'. Pathways to impact are tied to specific project aims and target audiences.

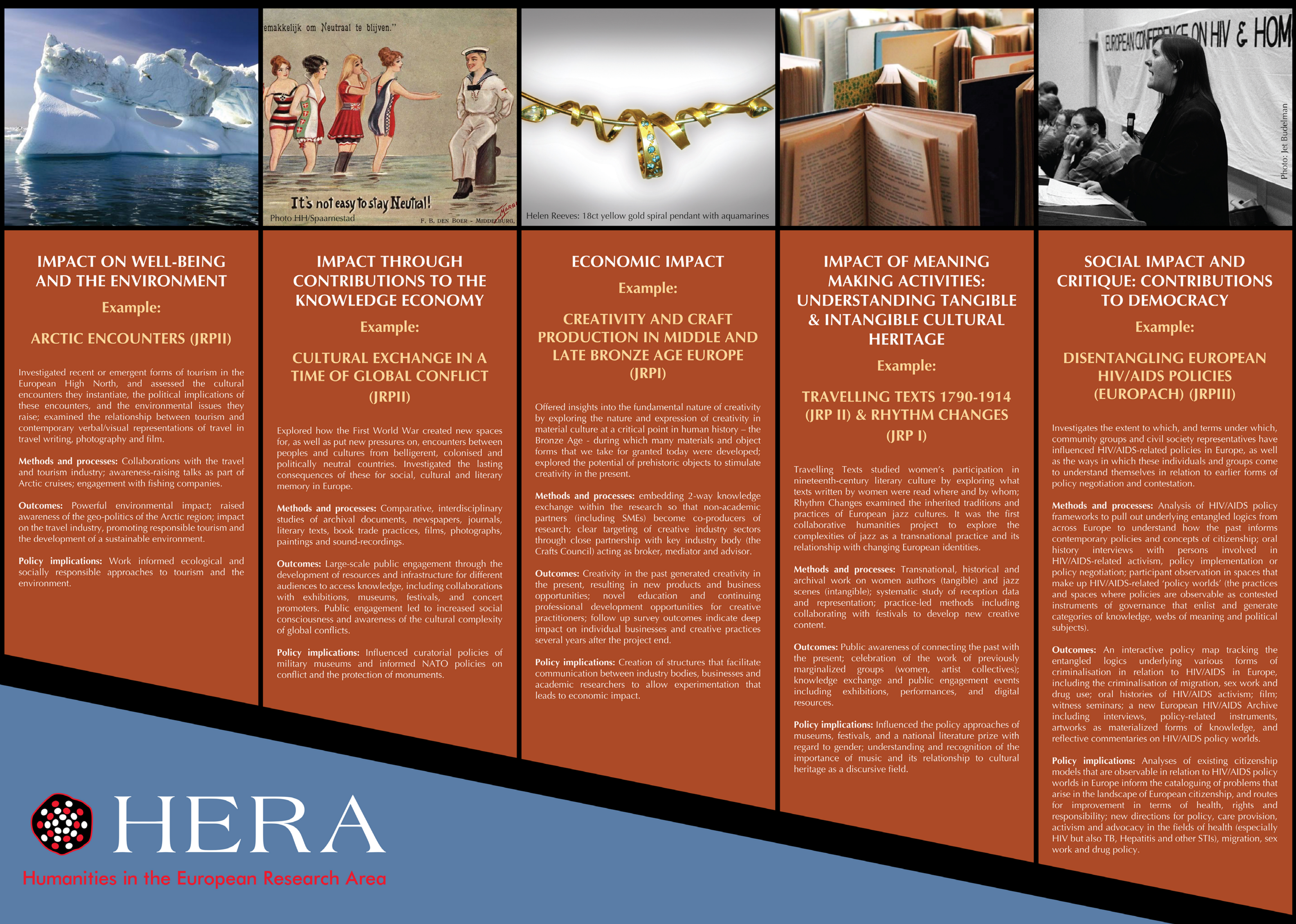

Historical, cultural, artistic and philosophical knowledge is indispensable for understanding humanity's past, for dealing with the key societal challenges of the present, and for imagining possible futures. 